\title{
Information preferences for the evaluation of coastal development impacts on ecosystem services: A multi-criteria assessment in the Australian context
}

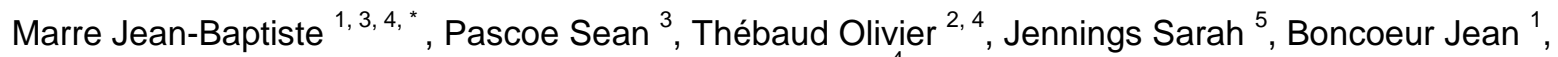 \\ Coglan Louisa ${ }^{4}$
}

${ }^{1}$ Université de Bretagne Occidentale, UMR AMURE, Brest, France

2 Ifremer, UMR M101, AMURE, Unité d'Économie Maritime, Brest, France

${ }^{3}$ CSIRO Wealth from Oceans Flagship, Marine and Atmospheric Research, Brisbane, Australia

${ }^{4}$ School of Economics and Finance, Queensland University of Technology, Brisbane, Australia

${ }^{5}$ Tasmanian School of Business and Economics, University of Tasmania, Hobart, Australia

* Corresponding author : Jean-Baptiste Marre, email address : jean-baptistem@spc.int

\begin{abstract}
:
Ecosystem based management requires the integration of various types of assessment indicators. Understanding stakeholders' information preferences is important, in selecting those indicators that best support management and policy. Both the preferences of decision-makers and the general public may matter, in democratic participatory management institutions. This paper presents a multi-criteria analysis aimed at quantifying the relative importance to these groups of economic, ecological and socioeconomic indicators usually considered when managing ecosystem services in a coastal development context. The Analytic Hierarchy Process (AHP) is applied within two nationwide surveys in Australia, and preferences of both the general public and decision-makers for these indicators are elicited and compared. Results show that, on average across both groups, the priority in assessing a generic coastal development project is for the ecological assessment of its impacts on marine biodiversity. Ecological assessment indicators are globally preferred to both economic and socio-economic indicators regardless of the nature of the impacts studied. These results are observed for a significantly larger proportion of decision-maker than general public respondents, questioning the extent to which the general public's preferences are well reflected in decision-making processes.
\end{abstract}




\section{Highlights}

- We examine information preferences for ecosystem services assessment indicators. We use the analytic hierarchy process in the context of coastal development. We compute relative weights from decision-makers and the general public in Australia. Ecological assessment indicators are preferred to economic or socio-economic ones - The representation of general public's preferences by decisionmakers is questioned.

Keywords: Analytic hierarchy process, Australia, Coastal development, Ecosystem services assessment, Information preferences, Multi-criteria analysis 


\section{Introduction}

There is a call for methodologies and approaches to assess and integrate ecosystem services (ES) into interdisciplinary evaluation frameworks (Spash, 2008; Vatn, 2009; Lopes and Videira, 2013; Martín-López et al., 2014). ES values span multiple dimensions (O`Neill et al., 2008; Vatn, 2009; Chan et al., 2012; Martín-López et al., 2014) and it has increasingly been argued that the process of ES assessment should encompass economic assessment (measured, e.g., via dollar values), ecological assessment (measured, e.g., via biophysical indicators), and socio-cultural assessment (tracked, e.g., via qualitative analyses), alongside institutional analyses (Spash and Carter, 2001; De Groot et al., 2002; Vatn, 2005 \& 2009).

Participatory and deliberative approaches are deemed to play a valuable role in ES assessment (James and Blamey, 2005; Spash, 2008; Vatn, 2009; Antunes et al., 2009; Garmendia et al., 2010; Lopes and Videira, 2013) The importance of active stakeholder participation in ecosystem management and decision-making has increasingly been acknowledged, and this is now supported and integrated in various recent policies worldwide (Reed, 2008; Lopes and Videira, 2013; Rogers, 2013). In particular, public participation has been advocated as a possible way to improve ecosystem management decision-making processes (Reed 2008). This is consistent with the view that it is the public's democratic right to participate in environmental policy and decision-making (Rogers, 2013).

Accounting for preferences and expectations of both decision-makers and the general public is therefore crucial in such participatory integrated management frameworks. For instance, concern about social license“ could lead to decision-makers favouring the use of indicators that are familiar to and accepted by the general public. Populations which are increasingly concerned about and involved in management decisions (Reed, 2008; Rogers, 2013) will expect transparent and understandable decision-making processes. On the other hand, the 
need for indicators that best track the actual performance of management implies that decision-makers may favour indicators regardless of their public acceptability. In addition, both decision-makers and the general public may favour the use of particular indicators if they believe that they are likely to favour outcomes that are consistent with a particular _agenda' or can be easily manipulated. In particular indicators that emphasize the distributional trade-offs between different social groups may be used to fuel conflict, or deliberately ignored to avoid it.

Both the need for a participatory framework in policy development and ecosystem assessment processes (Lopes and Videira, 2013), and the importance of articulating and integrating the different dimensions of ES (Martín-López et al., 2014), raise the issue of how economic, ecological and social criteria are weighted and balanced by both decision-makers and the general public when assessing the consequences of changes in ES.

Multi-criteria Analysis (MCA) can help address such questions. MCA encompasses a collection of theories, methodologies and techniques to explicitly integrate and balance a set of decision criteria (Figueira et al., 2005). MCA has been widely used in ES management (e.g. Vaidya and Kumar, 2006; Bryan et al., 2010; Prato and Herath, 2012; Fontana et al., 2013), because the complexity, the uncertainty, the conflicts as well as the diversity of stakeholders involved in ES management call for such procedures (Martinez-Alier, 1998; Munda, 2004; Gowdy and Erickson, 2005; Liu et al., 2010; Garmendia et al., 2010). There are many cases studies where MCA has allowed an in-depth analysis and quantification of the trade-offs between various economic, ecological and social management objectives or criteria. In particular, the Analytic Hierarchy Process (AHP), which allows evaluation of the relative priorities placed on competing criteria that can be organized hierarchically (Saaty, 1977), has been extensively used (e.g. Vaidya and Kumar, 2006). 
However, the authors are not aware of any MCA study that has examined quantitatively the information preferences for competing economic, ecological or social ecosystem assessment indicators in a generalised management context i.e. that aimed at estimating the relative importance weight attached by stakeholders to various indicators tracking the multiple consequences of changes in ES, for management decision-making. The authors also know of no other studies that compared the weight placed by both the general public and decisionmakers on such indicators.

The general objective of this work is to elicit and compare the weights attached by decisionmakers and the general public to three main categories of indicators to assess changes in ES in a coastal development context. These indicators - namely (1) economic valuation indicators; (2) ecological indicators; and (3) socio-economic indicators - are the most commonly encountered in the field“ in ES management, and mostly recommended by mainstream economists, ecologists, the social media and politicians. These weights are estimated in the context of a generic coastal development scenario where these indicators can be used to assess the impact of coastal development on three areas of consequences: on marine commercial activities, on marine recreational activities and on marine biodiversity. The analysis is undertaken in the context of Australian coastal management using AHP to elicit preferences from two nationwide surveys.

The paper is organized as follows. Section 2 presents the AHP technique, the development and design of the AHP-based model, its application to the Australian coastal management context and the data collection, as well as the different statistical methods used to analyse the AHP results. Section 3 shows the results of the AHP application for Australian decisionmakers and general public, and their subsequent analysis: the elicitation of weights representing stakeholders' ${ }^{6}$ information preferences and the distribution of these preferences across the two populations. Section 4 discusses these results, and section 5 concludes. 


\section{Material and method}

\subsection{The Analytic Hierarchy process}

The authors selected the AHP technique in view of its numerous applications in the domain of ecosystem and land use management (Herath, 2004; Wattage and Mardle, 2005; Vaidya and Kumar, 2006; Ho, 2008; Diaz-Balteiro and Romero, 2008; Fontana et al., 2013), including coastal and marine ecosystems management (e.g. Himes, 2007; Pascoe et al., 2009a and 2009b; Innes and Pascoe, 2010; Tian et al., 2013). The AHP proposes a framework for the elicitation and analysis of preferences for criteria, objectives or various management alternatives in a hierarchical manner (Saaty and Vargas, 2001). The strengths and weaknesses of the AHP method in comparison to other methods have been discussed extensively (e.g. Saaty, 1994; Figueira et al., 2005; Linkov et al., 2006; Vaidya and Kumar, 2006; Ho, 2008; Sipahi and Timor, 2010). The reviews point to the fact that AHP has a robust theoretical base in terms of preference elicitation even though it has received criticisms, and that there are a substantial number of successful applications in many management or decision domains (Ishizaka and Labib, 2011).

Developing and conducting an AHP involves four main steps (Wattage and Mardle, 2005). The first step is the identification of the management problem and the selection of the competing criteria followed by their organization within a hierarchical tree.

The second step is the development of the pairwise comparisons that will be used to determine the individuals ${ }^{6}$ priorities or preferences towards the criteria based on the hierarchical tree. These pairwise comparisons are usually based on a nine-point intensity of importance scale (Saaty, 1977). Once the data are obtained by surveying stakeholders, the third step is the analysis of the individual preferences obtained, based on the relative weights they attributed to each criteria. 
The relative weights are derived from a pairwise comparison reciprocal matrix (A) of judgements and are found by solving (Saaty, 1977):

$$
\sum_{j=1}^{n} a_{i j} w_{j}=\lambda_{\max } w_{i} \quad \forall i\left(a_{j i}=1 / a_{i j} \text { and } a_{i j}>0\right)
$$

where indices $i$ and $j$ represent a pair of criteria, $\lambda_{\max }$ the principal eigenvalue, and the weights $w_{j}$ are normalised appropriately. The solution is typically known as the principal right eigenvector.

The estimation of relative weights makes sense only if derived from consistent or near consistent matrices (Saaty, 1977). Consistency check must therefore be applied, i.e. it is necessary to check whether respondents were inconsistent in completing the set of pairwise comparisons. The matrix $\mathrm{A}$ is said to be consistent when $w_{j i}=a_{i j} w_{i j}$ and its principal eigenvalue, $\lambda_{\max }$, is equal to $n$ (i.e. the dimension of $\mathrm{A}$ ). When $\mathrm{A}$ is inconsistent, then $\lambda_{\max }>n$ and the variance of the error incurred in estimating $a_{i j}$ can be shown to be $\left(\lambda_{\max }-n\right) /(n-1)$ (Saaty and Vargas, 2001). Saaty (1977) defined this variance as the consistency index (CI). In order to measure the inconsistency present within an individual's AHP responses, he proposed dividing this $\mathrm{CI}$ by a random index (RI) corresponding to the average CI of 500 randomly filled judgement matrices using the 9-point scale. The consistency ratio $(\mathrm{CR})$ is then given by: $\mathrm{CR}=\mathrm{CI} / \mathrm{RI}$.

If $\mathrm{CR}$ is less than $0.1^{1}$, then the matrix is considered to have an acceptable level of consistency and the derived weights are considered to be valid as their variance is low enough. With a $\mathrm{CR}>0.1$, the paired comparisons matrix should be revised (i.e. the respondents should be asked to review and revise their comparisons ratings). If this is not

\footnotetext{
${ }^{1}$ This cut-off rule to declare the matrix inconsistent is, to a certain extent, flexible and has been discussed and debated by several authors (Ishizaka and Labib, 2011; Whitmarsh and Wattage, 2004). Saaty (1994) set the acceptable CR values for different matrix sizes.
} 
possible, or if the revised comparison matrix remains inconsistent, the individuals' responses should not be included in the final sample.

Weights corresponding to consistent judgements are estimated. These weights obtained from the different pairwise comparisons corresponding to each level of the tree can then be associated to one another in view of their hierarchical relation. This allows the computation of overall weights in order to derive preferences associated with the whole management problem.

The last stage in the AHP process is to aggregate these individual weights to derive preferences at the stakeholders' group level.

\subsection{The model}

The development of the hierarchical tree and design of the associated management framework was conducted in consultation with researchers involved in coastal management, from various organizations. The AHP was kept as simple as possible to minimize the risk of cognitive burden and fatigue from respondents.

\subsubsection{Management problem}

The objective was to develop a model that could be related to numerous coastal development cases, with a possible application to Australia. It is likely, however, that individuals' preferences for assessment indicators differ depending on the specific coastal development context being considered. This calls for a compromise between the details required to describe a precise coastal development scenario and the need for a simply-framed hypothetical management problem.

The AHP survey was therefore developed on the basis of a hypothetical scenario involving a significant coastal development project, which was expected to have consequences on marine 
ecosystems and associated marine activities in the impacted coastal area. This area was assumed to be used intensively for many marine activities (e.g. commercial fisheries, recreational fisheries, recreational and tourism activities), and to contain ecosystems of international significance with an important diversity of habitats (e.g. wetlands, coral reefs, rocky reefs, mangroves, sea grass) and popular or unique species (e.g. whales, dolphins, turtles, dugongs).

The impacts of the hypothetical project on ES were synthesised into three categories of consequences: consequences on commercial activities (i.e. commercial fishing operations, diving and snorkelling operations, charter recreational fishing operations); consequences on non-commercial recreational activities (i.e. activities conducted on a private personal basis: recreational fishing, diving, snorkelling, surfing, boating, beach use); and consequences on marine biodiversity (e.g. diversity of marine habitats and species).

Survey respondents were told that several options were being considered for this development project, including alternative ways of managing project impacts.

\subsubsection{Assessment criteria}

To help choose which development option to approve (if any), the impacts of each option on ES were to be assessed using three types of information: economic valuation indicators, ecological indicators and socio-economic indicators. For each category of consequences (on commercial activities, recreational activities and marine biodiversity), each of these indicators was defined.

The indicators selected were those commonly used within each of the categories of consequences: (1) standard monetary values of ES (for example: profits of commercial activities); (2) ecological assessment indicators (for example: biomass of stocks targeted by commercial fisheries); and (3) socio-economic descriptors used regularly by stakeholders (for 
example, the revenue of commercial activities and employment). Complex terminology was avoided and key definitions were provided in a glossary accessible throughout the survey. Appendix A presents the definition of various indicators presented in the AHP.

\subsubsection{AHP structure and pairwise comparisons}

The AHP aimed to elicit the relative weights attached by stakeholders to: (1) changes in ES synthetised here as consequences on marine activities and marine biodiversity, and; (2) the different assessment of ES changes (economic, ecological and socio-economic).

Figure 1 shows the hierarchical tree representing the hypothetical management framework described above. The complexity of the management problem (to decide between various options for a coastal development project) is hierarchically structured according to three different objectives relating to the types of consequences that the development project may have, and three categories of assessment criteria that can be used to assess these consequences.

Based on this hierarchical tree, 12 pair-wise comparisons were developed using the nine point judgement scale. The first set of three comparisons related to the categories of consequences of the development project to be assessed. Three other sets, each of three comparisons, aimed at assessing the relative importance of using the three classes of indicators to assess each of the categories of consequences. Examples of the pairwise comparisons are presented in Appendix B. 


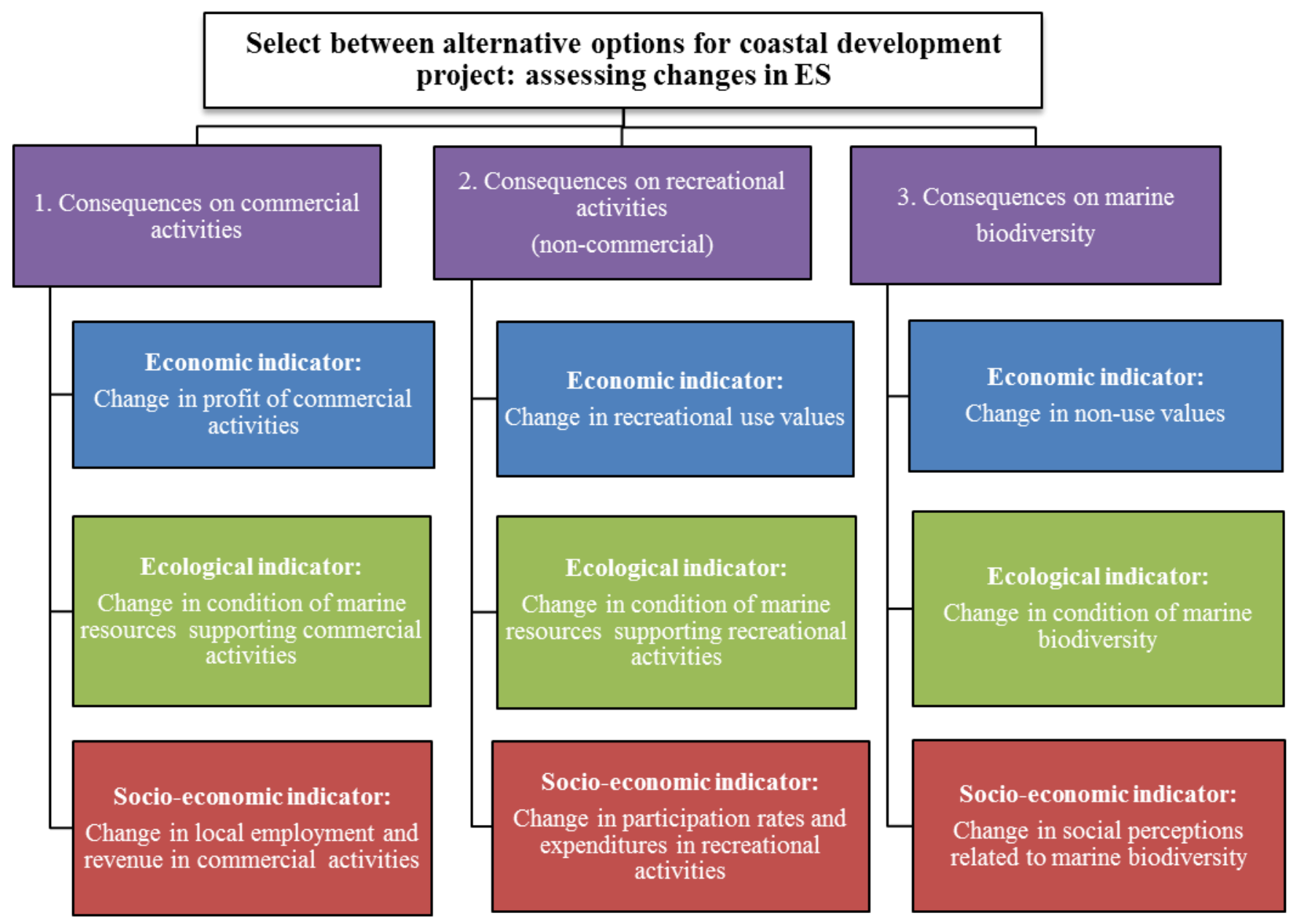

Figure 1 AHP Hierarchical structure

\subsection{Application in Australia}

This generic AHP model developed above was applied to the context of Australian coastal management, by referring to a project which was currently being planned in a coastal area in Australia.

Nation-wide online surveys were conducted ${ }^{2}$. The AHP hierarchical structure was presented and explained. Respondents were told that the coastal area where the project was taking place

\footnotetext{
${ }^{2}$ The AHP survey was actually a specific section of a broader survey which aimed at examining and documenting more generally the use of economic valuation of ecosystem services in decision-making. The AHP section was introduced in the survey to gather information on stakeholders' preferences foreconomic valuation in comparison to other indicators.
} 
was well known to them. This was to elicit better-defined preferences and mitigate the hypothetical nature of the exercise. This was also meant to make the respondents feel more concerned by the exercise, and potentially make it easier for them to rely on pre-existing preferences.

The rationale for the pairwise comparisons format was explained through a simple example, as well as the principles of relative importance and consistency implied by a set of pairwise comparisons. After each completed set of pair-wise comparisons, the respondents were provided with a consistency ratio indicating the consistency of their answers, and the weights implied by their ranking were also shown (if consistent). When the scores were inconsistent (i.e. consistency inferior to $90 \%$ ), the respondents had the opportunity to revise their original comparison responses, but were allowed to leave their original response unchanged so that they were not compelled to blindly submit to the consistency rule. Follow-up questions regarding respondents' perceptions of the AHP were added.

The two nationwide surveys targeted two populations: decision-makers and the general public. A representative sample of 250 individuals from the general population was used, with a representative balance of age categories (older than 18 years old), gender and geographical locations ${ }^{3}$. A random stratified sampling method based on quotas was used to ensure the selection of the 250 individuals. The decision-maker sample was based on a list of 450 individuals identified as being directly involved in Australian coastal and marine management. The list contained an important diversity of stakeholders, with different roles at different steps and levels of decision-making:

\footnotetext{
${ }^{3}$ The proportions of populations for the different states in Australia are: 32.1\% for New South Wales, 24.8\% for Victoria, 20.1\% for Queensland, 10.7\% for Western Australia, 7.3\% for South Australia, 2.2\% for Tasmania, $1.6 \%$ for Australian Capital Territory and 1\% for Northern Territory (Australian Bureau of Statistics, 2013). The median age is 38 years old and the male/female ratio is one (Australian Bureau of Statistics, 2013).
} 
- Members of governments from different Departments (e.g. fisheries, environment, tourism, land management) and in different positions (such as manager, scientist, executive director, etc.) at both national and state levels;

- Members of governments' agencies/bodies involved in coastal and marine management (e.g. the Australian Fisheries Management Authority or Environmental Protection Agencies);

- Members of regional and local governments and committees in charge of coastal and marine management issues;

- Researchers (from different research organizations) who are part of committees or consultation processes;

- Important marine industry or marine activity representatives (e.g. recreational or commercial fishing).

\subsection{Statistical analysis}

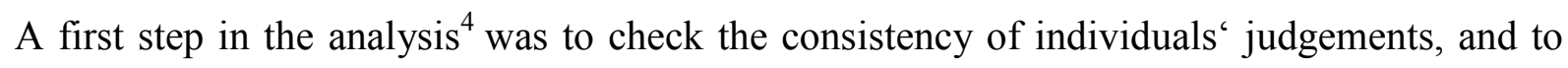
reject both inconsistent and unreliable answers $=$. The weights corresponding to consistent preferences were then computed and aggregated using the arithmetic mean as in various applications (e.g. Mardle et al., 2004; Wattage and Mardle, 2005; Pascoe et al., 2009a, Innes and Pascoe, 2010). Statistically significant differences between decision-makers ${ }^{`}$ and general public's aggregated weights were assessed using two-sample t-tests.

A second step was to use cluster analysis to look for and define homogenous groups of preferences among the overall sample, as done in many AHP studies (e.g. Mardle at al., 2004; Wattage and Mardle, 2005; Tsai and Su, 2005; Pascoe et al., 2009a; Zoppi, 2012; SalazarOrdonez et al., 2013). A hierarchical clustering based on Ward's minimum variance method

\footnotetext{
${ }^{4}$ All the statistical analyses were conducted with $\mathrm{R}$.
} 
was used. The number of clusters was selected by examining the structure of the dendrogram, with the objective to keep this number low enough to make results` interpretation succinct and meaningful. A cluster analysis was conducted on a single pooled sample of general public and decision-makers, and proportions of each population in each cluster were identified. This allowed us to examine whether these two populations shared similar preference structures.

\section{Results}

\subsection{Profile of respondents}

The surveys took place between September and October 2013. In total, 256 respondents from the general public and 64 decision-makers completed the AHP. Socio-economic characteristics of the individuals retained for the analysis are presented in table 1 , for each sample.

Among the decision-makers sample, $64 \%$ of individuals declared working on marine areas and species conservation, $56 \%$ on coastal development, $42 \%$ on recreational activities and tourism, $34 \%$ on coastal and marine pollution, $23 \%$ on commercial fisheries and $14 \%$ on indigenous and customary use. Their work focused on the eight jurisdictions (each State, the Northern Territory and the Federal level), across all management contexts.

Table 1 Socio-demographic characteristics of the general public and decision-maker samples retained for analysis

\begin{tabular}{|c|c|c|}
\hline & General public & Decision-maker \\
\hline Age (average) & 44 (s.d. $=15$; range: $18-74)$ & 42 (s.d. $=10 ;$ range: $18-74)$ \\
\hline Gender (average) & $49 \%$ male & $69 \%$ male \\
\hline Level of Education (average) & Level 3 ${ }^{\mathrm{i}}$ (s.d. $\left.=1.6\right)$ & Level $5^{\mathrm{i}}$ (s.d. $\left.=1.1\right)$ \\
\hline Field of education & Management and commerce: $20 \%$ & Natural and physical science: $48 \%$ \\
(mostly cited categories) & Health: $11 \%$ & Agriculture \& environmental studies: $52 \%$ \\
& Engineering and technologies: $9 \%$ & Management and commerce: $12 \%$ \\
& Information technology: $8 \%$ & Society and culture: $16 \%$
\end{tabular}




\begin{tabular}{|c|c|c|}
\hline & $\begin{array}{l}\text { Society and culture: } 8 \% \\
\text { Education: } 7 \% \\
\text { Natural and physical science: } 7 \%\end{array}$ & Engineering and technologies: $9 \%$ \\
\hline Work experience & $\begin{array}{c}\text { Business: } 20 \% \\
\text { Finance: } 15 \% \\
\text { Economics: } 3 \% \\
\text { Biological conservation: } 2 \% \\
\text { Other (none of the above): } 60 \%\end{array}$ & $\begin{array}{c}\text { Environmental management: } 91 \% \text {, } \\
\text { Biological conservation: } 53 \% \text {, } \\
\text { Economics: } 19 \% \\
\text { Business: } 17 \% \\
\text { Finance: } 6 \%\end{array}$ \\
\hline Geographic Location & $\begin{array}{c}\text { NSW: } 31 \% \text {, Vic: } 25 \% \text {, Qld: } 21 \% \text {, SA: } \\
\text { 8\%, WA: } 9 \% \text {, NT: } 0.4 \% \text {, Tas: } 3 \% \text {, } \\
\text { ACT: } 2 \%\end{array}$ & $\begin{array}{c}\text { NSW: } 25 \% \text {, Vic: } 6 \% \text {, Qld: } 17 \% \text {, SA: } 14 \% \text {, WA: } \\
\text { 17\%, NT: } 6 \% \text {, Tas: } 11 \% \text {, ACT: } 3 \%\end{array}$ \\
\hline
\end{tabular}

" 6 being "post graduate" and 1 being "secondary"; 3 corresponds to "diploma”; 4 to "bachelor degree”; 5 to "graduate diploma"

NSW: New South Wales, Vic: Victoria, Qld: Queensland, WA: Western Australia, SA: South Australia, Tas: Tasmania, ACT: Australian Capital Territory, NT: Northern Territory

s.d.: standard deviation

\subsection{Elicitation of weights of stakeholder preferences}

\subsubsection{Consistency and protest answers}

The proportions of inconsistent responses $(\mathrm{CR}>10 \%)$ among the respondents were substantial: $36 \%$ of the general public, and $23 \%$ of the decision-makers. This was probably due to the fact that the AHP was conducted online, although the results are actually better in this respect than in other AHP work involving face-to-face interviews, where inconsistency reached more than $50 \%$ of the sample (e.g. Wattage and Mardle, 2005). More broadly, inconsistency is often substantial in many AHP studies (e.g. Whitmarsh and Mardle, 2005; Pascoe et al., 2009), especially concerning the general public (e.g. Qureshi and Harrison, 2003; Wattage and Mardle, 2005)

Furthermore, around $20 \%$ of respondents in the decision-makers sample and $25 \%$ from the general public sample indicated that their responses to the AHP might not reflect their preferences for various reasons (with a majority stating this was because they did not 
understand the consistency issue, especially in the general public). Responses from these individuals were all carefully examined, by looking at both the reasons they mentioned and their AHP scores and associated consistency, in order to identify protest answers ${ }^{5}$.

The final proportions of respondents from the general public and decision-maker samples retained for the analysis, accounting for both consistency and protest answers, are respectively equal to $49 \%$ and $73 \%$. This corresponds to 126 respondents from the general public and 47 from the decision-makers. Several AHP studies applied to coastal and marine ecosystems management and not necessarily based on online surveys did end up with high proportions of discarded observations (e.g. Wattage and Mardle, 2005; Pascoe et al., 2009).

\subsubsection{Aggregated weights}

Figure 2 and 3 represent the aggregated weights graphically associated with the categories of consequences to be assessed, and with the economic, ecological and socio-economic assessments of these consequences, for both samples.

Basic statistics regarding the lower level objectives are presented in table 2. Two Sample ttests were run to compare the mean values observed for the two groups.

\footnotetext{
${ }^{5}$ In both samples, many scores from these individuals were either inconsistent or set to be equal among all alternatives. In the latter case, this was interpreted as a form of - ptest answer" (i.e. as a refusal to make any comparisons). These inconsistent or - potest answers" were discarded from the analysis.
} 


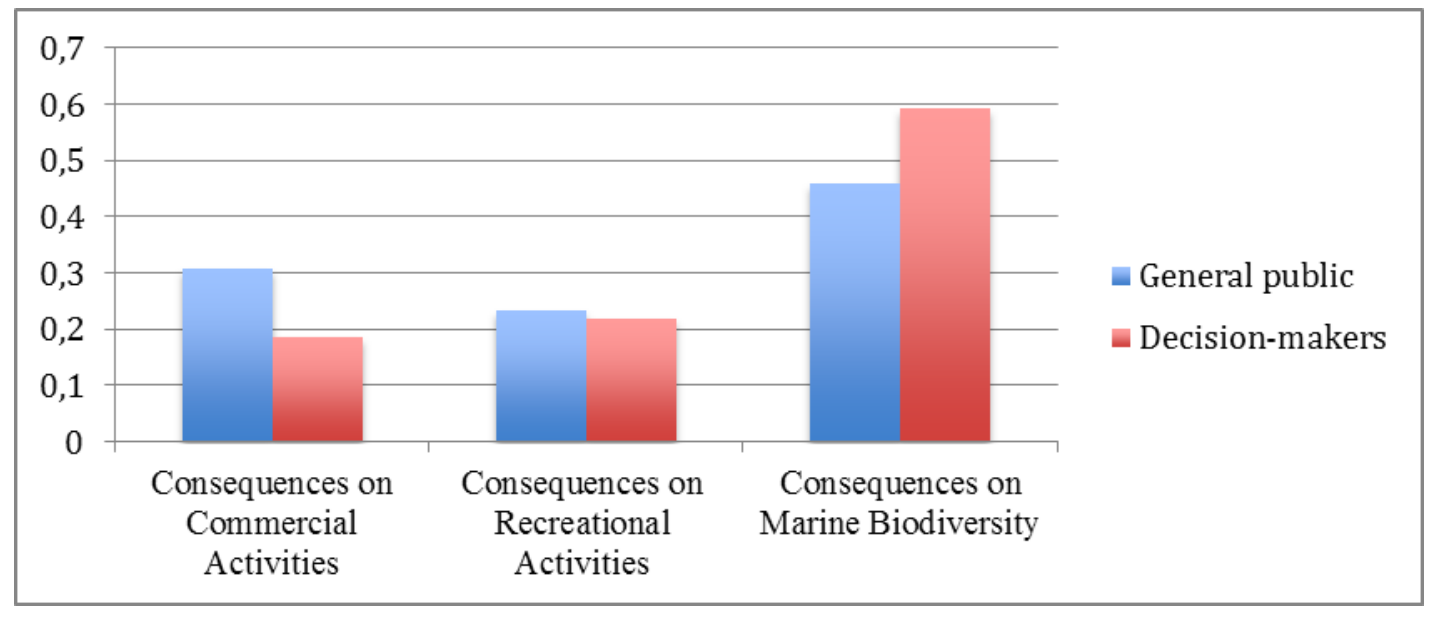

Figure 2 General public and decision-makers aggregated weights associated with categories of consequences to be assessed

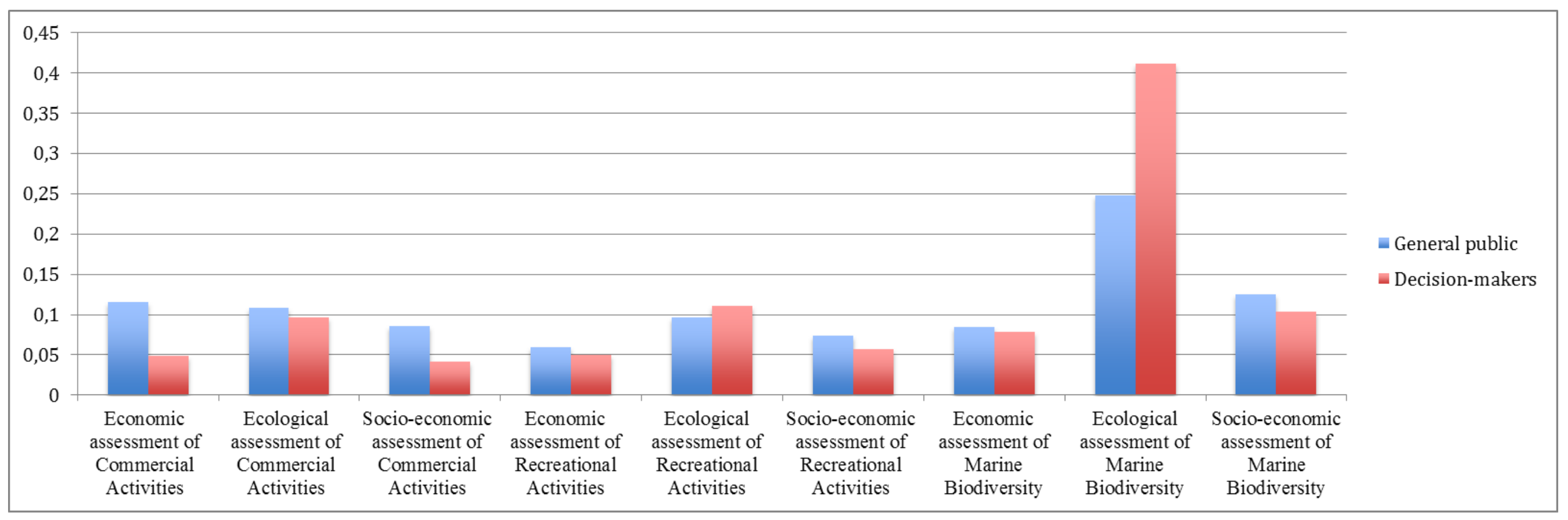

Figure 3 General public and decision-makers aggregated weights associated with economic, ecological and socio-economic assessment of

consequences 
Table 2 Weights associated with economic, ecological and socio-economic assessment of each category of consequences: statistics for general public and decision-makers

\begin{tabular}{|c|c|c|c|c|c|c|}
\hline & \multicolumn{3}{|c|}{ General public $(\mathrm{n}=126)$} & \multicolumn{3}{|c|}{ Decision-makers $(n=47)$} \\
\hline & median & mean & s.d. & median & mean & s.d. \\
\hline W Com Econ & 0.035 & $0.116 * *$ & 0.155 & 0.023 & $0.049 * *$ & 0.057 \\
\hline W Com Ecol & 0.081 & 0.108 & 0.088 & 0.083 & 0.097 & 0.061 \\
\hline W Com SE & 0.061 & $0.086^{* *}$ & 0.085 & 0.024 & $0.042 * *$ & 0.051 \\
\hline W Rec Econ & 0.030 & 0.060 & 0.073 & 0.017 & 0.050 & 0.091 \\
\hline W Rec Ecol & 0.073 & 0.097 & 0.089 & 0.077 & 0.111 & 0.101 \\
\hline W Rec SE & 0.044 & 0.074 & 0.096 & 0.038 & 0.057 & 0.079 \\
\hline W Bio Econ & 0.071 & 0.085 & 0.073 & 0.068 & 0.079 & 0.063 \\
\hline W Bio Ecol & 0.167 & $0.248^{* *}$ & 0.224 & 0.430 & $0.412 * *$ & 0.202 \\
\hline W Bio SE & 0.075 & 0.125 & 0.115 & 0.075 & 0.104 & 0.091 \\
\hline
\end{tabular}

According to the t-test results, some differences can be observed between the responses of decision-makers and the general public. Decision-makers gave more weight to the ecological assessment of consequences on marine biodiversity, whereas they gave less weight to the socio-economic indicators and economic indicators to assess commercial activities consequences.

The results also showed substantial variation among these weights and an important degree of dispersion. This high diversity of weights in each sample confirmed that a more detailed analysis was required, looking for possibly more homogenous groups of preferences.

\subsection{Cluster analysis results}

Results from the hierarchical cluster analysis on the pooled sample with decision-makers and general public respondents are presented in table 3 for the weights associated with the 
categories of consequences to be assessed and in table 4 for the weights associated with the economic, ecological and socio-economic assessments of these consequences.

Table 3 Hierarchical clusters for the pooled sample weights associated with consequences to be assessed

\begin{tabular}{l|c|c|c|c|} 
& Cluster 1 & Cluster 2 & Cluster 3 & Cluster 4 \\
\hline Commercial activities & 0.131 & 0.251 & 0.324 & $\mathbf{0 . 7 0 6}$ \\
Recreational activities & 0.135 & $\mathbf{0 . 6 0 5}$ & 0.266 & 0.132 \\
Marine biodiversity & $\mathbf{0 . 7 3 4}$ & 0.144 & 0.410 & 0.162 \\
\hline Proportions of individuals in cluster & 50.3 & 14.4 & 19.7 & 15.6 \\
\hline Proportions of GP in cluster (\%) & 44.4 & 15.9 & 19.0 & 20.6 \\
\hline Proportion of DM in cluster (\%) & 66.0 & 10.6 & 21.3 & 2.1
\end{tabular}

In both cases, four clusters were identified. Table 3 shows that half of individuals placed a largely dominant priority on the assessment of consequences on marine biodiversity. The three other groups contained each around 15 to $20 \%$ of individuals: one exhibited dominant priority for the assessment of consequences on recreational activities, another one exhibited dominant priority for the assessment of consequences on commercial activities, while the last group exhibited more balanced weights across all categories of consequences.

Table 4 shows that around $22 \%$ of individuals formed a homogenous preference with a highly dominant priority for the ecological assessment of the consequences on marine biodiversity. Another 30\% formed a group with dominant priorities attributed to the various assessments of the consequences on marine biodiversity with, by order of preference, ecological, socioeconomic and then economic indicators. A further $30 \%$ of individuals were found to attribute a largely dominant priority for the assessment of the consequences on commercial activities with the economic indicator first, followed by ecological and socio-economic ones. A last $14 \%$ formed a group with dominant priorities attributed to the assessment of the consequences 
on recreational activities, first with ecological, then with socio-economic and finally with economic indicators.

Table 4 Hierarchical clusters for the pooled sample weights associated with the assessment of development consequences

\begin{tabular}{l|c|c|c|c|}
\multicolumn{1}{c|}{ Lower level objectives } & Cluster 1 & Cluster 2 & Cluster 3 & Cluster 4 \\
\hline W Com Econ & 0.037 & 0.037 & 0.012 & $\mathbf{0 . 2 3 3}$ \\
W Com Ecol & 0.084 & 0.105 & 0.070 & 0.147 \\
W Com SE & 0.054 & 0.048 & 0.018 & 0.140 \\
\hline W Rec Econ & 0.026 & 0.110 & 0.011 & 0.095 \\
W Rec Ecol & 0.073 & $\mathbf{0 . 2 7 9}$ & 0.078 & 0.069 \\
W Rec SE & 0.052 & 0.188 & 0.019 & 0.069 \\
\hline W Bio Econ & $\mathbf{0 . 1 1 6}$ & 0.032 & 0.077 & 0.080 \\
W Bio Ecol & $\mathbf{0 . 3 4 9}$ & 0.115 & $\mathbf{0 . 6 3 2}$ & 0.093 \\
W Bio SE & $\mathbf{0 . 2 0 9}$ & 0.085 & 0.085 & 0.075 \\
\hline Proportions of individuals in cluster & $\mathbf{3 0 . 6}$ & $\mathbf{1 3 . 9}$ & $\mathbf{2 2}$ & $\mathbf{3 3 . 5}$ \\
\hline Proportion of GP in cluster (\%) & 27.8 & 13.5 & 17.5 & 41.3 \\
\hline Proportions of DM in cluster (\%) & 38.3 & 14.9 & 34.0 & 12.8
\end{tabular}

In both tables, the representation of both groups across all clusters confirmed the hypothesised heterogeneity of preferences within both populations. In addition, two of the clusters had similar proportions of the general public and decision-makers with respect to the samples sizes. These were:

- Clusters 2 and 3 for table 3, which corresponds to a group with dominant preferences for the assessment recreational consequences and a group with relatively balanced preferences for each type of consequences to be assessed;

- Clusters 1 and 2 for table 4, which corresponds to a group with dominant preferences for the various assessments of marine biodiversity consequences (the ecological one being higher), and with dominant preferences for the various assessments of consequences on recreational activities (the ecological one being higher). 
Finally, there were proportionally more decision-makers who placed a dominant priority on the assessment of marine biodiversity, with a high preference on ecological assessment; whereas there were proportionally more members of the general public sample who placed a dominant priority on the assessment of commercial activities, with a high preference on economic assessment.

\section{Discussion}

For the three categories of consequences of the development project on coastal and marine ecosystems, assessments using ecological indicators were on average systematically largely preferred to the other two indicators in both samples. The socio-economic indicators were coming next in terms of priority, followed by the economic ones (except for the consequences on commercial activities where the economic indicator is preferred on average to the socioeconomic one for both sample). In this context, ecological indicators were considered to be more important in development project appraisal than either economic valuation or various types of socio-economic indicators frequently encountered.

Ecological assessment indicators might have been perceived as providing the most objective information, or as the criteria guaranteeing that desired level are reached for economic and socio-economic indicators in the long run, reflecting for instance the importance of the dynamic ecological processes underpinning the delivery of ecosystem services (de Groot et al., 2010). The ecological discourse might therefore still be strongly established when assessing changes of ecosystem services and biodiversity, even changes related to commercial and recreational activities.

While both the decision-makers and the general public attributed on average a dominant priority to the consequences on marine biodiversity and their ecological assessment, the former placed on average substantially more weight on these. This was to the detriment of the 
weights placed on the economic and socio-economic assessment of the consequences on commercial activities. Both decision-makers and general public attributed on average the same weights to the consequences of recreational activities and their economic, ecological and socio-economic assessments.

The lower priority given to commercial activities by decision-makers might be because this sample included a majority of individuals working on conservation of marine areas and species $(60 \%)$ in comparison to individuals working in commercial activities $(20 \%)$, and a majority of individuals with a work experience in biological conservation in comparison to economics, business or finance ${ }^{6}$. Further, $80 \%$ of the decision-makers working on the management of commercial fisheries were also involved in coastal and marine conservation.

The globally low weights placed on economic valuation indicators by both populations may also be partly due to a lack of knowledge or familiarity with economic valuation from both populations (Laurans et al., 2013; Rogers et al., 2013). Besides, in the AHP formulation, the economic valuation indicators for the various consequences were defined as containing only one type of information whereas the ecological and socio-economic assessment indicators were defined as containing several types of information. The comparison exercise was thus somewhat unbalanced in this respect and this must be kept in mind when analysing the results ${ }^{7}$.

\footnotetext{
${ }^{6}$ This raises the issue of representativeness of the decision-making sample. It is hard however to clarify what a -apresentative" sample would be. Without descriptive statistics for this population, the approach was to target an important diversity of decision-makers.

${ }^{7}$ One could argue that some respondents may not have clearly understood the difference between the economic valuation indicators and the socio-economic ones. However, none of the respondents raised such a concern, and efforts were made to clearly distinguish between the two during the AHP through their definitions (Appendix A).
} 
The authors also showed the existence of preference heterogeneity, and identified four homogenous groups of preferences in the pooled sample for both the weights attributed to the various consequence categories and the ones attributed to their measurement through the three types of indicators. Both categories of stakeholders were represented in all four preference groups, thus showing that a certain level of convergence in opinions exists. Nevertheless, while two groups exhibited strong convergence, suggesting an accurate representation of general public's preferences by decision-makers (that is: comparable proportions of decision-makers and general-public in the identified homogenous groups), two other groups showed poor representation, indicating a potential for important mismatch of both stakeholders' preferences. In the group where very large priority was given to the ecological assessment of marine biodiversity, the ratio of decision-makers to the members from the general public was around two to one; while in the group where the priority was for the various assessments of the consequences commercial activities, the ratio of members from the general public to the decision-makers was around three to one.

This divergence in terms of priorities for the assessment indicators accords with conclusions from the work of Rogers (2013) in Australia where preferences of general public and marine experts were found to differ significantly in the context of marine reserve assessment. However, in the present case, the decision-makers whose preferences did not reflect those expressed by the public did not only have an informative or consultative role: around $40 \%$ of them stated playing a decisive role in the decision (deciding whether or not a decision is implemented), and around $80 \%$ a contributive one (contributing to the final decision and/or management plan $)^{8}$. Therefore, in some situations, preferences of those involved in early stages of the decision process (such as individuals involved in research and information

\footnotetext{
${ }^{8}$ In comparison, around $20 \%$ of decision-makers whose preferences were reflecting public ones declared playing a decisive role, while around $50 \%$ declared playing a contributive one.
} 
provision), which tends to reflect better public preferences, might differ from preferences of those who make decisions. Information provided in early stages might thus be used selectively, and some of it ignored.

A potential limit concerns the hypothetical nature of the AHP management problem. In total $10 \%$ of decision-makers and $15 \%$ of the general public samples stated that their answers might not reflect really well their true preferences because they felt they needed more information regarding the coastal development scenarios or indicators being compared. Therefore, as mentioned before, the potential lack of familiarity or knowledge of the indicators being compared might also be an issue. Applying the same model to a real-world coastal management scenario would provide interesting insights in this respect, and this AHP model is currently being applied in the context of the Iroise Marine Natural Park management in France.

\section{Conclusion}

The objective of this work was to examine the information preferences of both the general public and decision-makers for commonly encountered ES assessment indicators in a coastal development management contexts. The approach, based on the AHP technique, was applied in two national online surveys in Australia focusing on a representative sample of the Australian population and on a sample of decision-makers involved in coastal management. It proposed a hypothetical coastal development scenario where the main consequences of the development project on coastal ecosystem services (commercial activities, recreational activities and marine biodiversity) could be assessed using three alternative evaluation indicators: economic valuation, ecological assessment and socio-economic assessment.

On average, ecological assessment indicators were generally preferred, even when looking at commercial and recreational impacts. In comparison to the general public, decision-makers 
considered the assessment of marine biodiversity as more important, and the commercial dimension as less important. They also placed higher weights on the various ecological assessment indicators, and lower weights on the economic and socio-economic indicators. This raises the question of the representation of preferences of the general public (and interests in commercial and socio-economic dimensions) in the sample of decision-makers which was interviewed, and potentially in decision-making processes.

Since resources for ecosystem assessment are often limited, with a subsequent need to optimize data collection, these results might have implications for monitoring and related budget allocation decisions, in the context of coastal development. The AHP model presented in this work is also generic enough to allow conducting similar applications in many other regions with various ecological and socio-economic contexts.

\section{Acknowledgements}

The data used in this manuscript were derived from a survey supported by the Marine Biodiversity Hub of the Australian Government's National Environmental Research Program. Within the Hub, the authors are grateful to Dr Nic Bax from CSIRO and Paul Hedge from University of Tasmania for their help. The authors are also grateful to the CSIRO Wealth from Ocean flagship for supporting this work, as well as the Australian Fisheries Research Development Corporation (FRDC project 2008/306). The authors thank all the individuals that participated in the surveys.

The analyses presented here are only the authors' ${ }^{6}$ and do not reflect positions of the organizations they work for and of project funders. 


\section{Appendix A: Assessment indicators used in the AHP}

\section{Box 1: Definition of the indicators to assess the consequences on commercial activities}

Economic indicator: Profit (revenue-costs) of commercial activities including fishing operations, diving and snorkelling operations, charter and recreational fishing operations

Ecological indicator: Condition of the stock and habitats of the species targeted by commercial fisheries and chartered recreational fisheries (e.g. abundance of commercial fish); and condition of the stock and habitats of the species supporting recreational activities offered by operators (e.g. whales)

Socio-economic indicator: Local employment in the commercial activity sector, and revenue* from commercial activities (e.g. value of sales directly derived from landings)

*Defined in the glossary

Box 2: Definition of the indicators to assess the consequences on non-market recreational activities

Economic indicator: Recreational use values*, that is to say asking people through surveys or estimating through people's behaviours their willingness to pay* for recreational marine activities and associated marine ecosystem features

Ecological indicator: Condition of the stock and habitats of species that are of primary importance to recreational activities (specific fish species targeted by recreational fishing, popular species for diving/snorkelling); condition of specific aesthetic assets (such as water clarity, specific underwater or beach landscapes...)

Socio-economic indicator: Participation rates in non-commercial recreational activities (from local users and tourists) and expenditures of recreational users

*Defined in the glossary 
Box 3: Definition of the indicators to assess the consequences on marine biodiversity

Economic indicator: Non-use values*, that is to say asking people through surveys how much they are willing to pay for preserving marine ecosystems without any consideration of their current or future uses

Ecological indicator: Condition of marine biodiversity assessed by several indicators (condition of species that have special conservation status, condition of key species or structural components of the ecosystem, or condition of physical-chemical components of the ecosystem)

Socio-economic indicator: Information through opinion polls and surveys about social perceptions of the status of marine biodiversity, and about the importance of marine biodiversity for populations (such as moral or spiritual importance)

*Defined in the glossary 


\section{Appendix B: Example of pairwise comparisons}

Below is an example of a group of three pairwise comparisons used in the AHP (out of the 4 groups of three pairwise comparisons).

Example:

Which indicator do you consider more important to use when assessing consequences of the development project on marine non-commercial recreational activities?

\begin{tabular}{l}
\hline $\begin{array}{l}\text { Economic indicator: change in profit of } \\
\text { commercial activities }\end{array}$ \\
\begin{tabular}{|c|c|c|c|c|c|c|c|c|c|c|c|c|c|c|c|c|}
\hline & $\begin{array}{c}\text { Ecological indicator: change in condition of } \\
\text { marine resources supporting commercial } \\
\text { activities }\end{array}$ \\
\hline 9 & 8 & 7 & 6 & 5 & 4 & 3 & 2 & 1 & 2 & 3 & 4 & 5 & 6 & 7 & 8 & 9 \\
\hline Significantly more important & Equal & Significantly more important \\
\hline
\end{tabular}
\end{tabular}

Economic indicator: change in profit of commercial activities

Socio-economic indicator: change in local employment and revenue in commercial

\begin{tabular}{|c|c|c|c|c|c|c|c|c|c|c|c|c|c|c|c|c|}
\hline \multicolumn{17}{|c|}{ activities sector } \\
\hline & & & & & & & & Q1 & & & & & & & & \\
\hline 9 & 8 & 7 & 6 & 5 & 4 & 3 & 2 & 1 & 2 & 3 & 4 & 5 & 6 & 7 & 8 & 9 \\
\hline
\end{tabular}

\begin{tabular}{|ccc|cc|c|c|c|c|}
\hline Significantly more important & Equal & & Significantly more important
\end{tabular}

Ecological indicator: change in condition of marine resources supporting commercial activities
Socio-economic indicator: change in local employment and revenue in commercial activities sector

\begin{tabular}{|c|c|c|c|c|c|c|c|c|c|c|c|c|c|c|c|c|}
\hline \multirow{2}{*}{\multicolumn{8}{|c|}{ aciovities }} & & & & & & & \multirow{2}{*}{\multicolumn{3}{|c|}{ activitues sector }} \\
\hline & & & & & & & & Q1 & & & & & & & & \\
\hline 9 & 8 & 7 & 6 & 5 & 4 & 3 & 2 & 1 & 2 & 3 & 4 & 5 & 6 & 7 & 8 & 9 \\
\hline
\end{tabular}




\section{References}

Antunes, P., Kallis, G., Videira, N., Santos, R., 2009. Participation and evaluation for sustainable river basin governance. Ecological Economics 68 (4), 931-939.

Bryan, B.A., Grandgirard, A., Ward, J.R., 2010. Quantifying and Exploring Strategic Regional Priorities for Managing Natural Capital and Ecosystem Services Given Multiple Stakeholder Perspectives. Ecosystems 13 (4), 539-555.

de Groot, R.S., Alkemade, R., Braat, L., Hein, L., Willemen, L., 2010. Challenges in integrating the concept of ecosystem services and values in landscape planning, management and decision making. Ecological Complexity 7 (3), 260-272.

Diaz-Balteiro, L., Romero, C., 2008. Making forestry decisions with multiple criteria: A review and an assessment. Forest Ecology and Management 255, 3222-3241.

Figueira, J., Greco, S., Ehrogott, M. (Eds), 2005. Multiple Criteria Decision Analysis: State of the Art Surveys. International Series in Operations Research \& Management Science 78, 1048p.

Fontana, V., Radtke, A., Fedrigotti, V.B., Tappeiner, U., Tasser, E., Zerbe, S., Buchhol, T., 2013. Comparing land-use alternatives: Using the ecosystem services concept to define a multi-criteria decision analysis. Ecological Economics 93, 128-136.

Garmendia, E., Gamboa, G., Franco, J., Garmendia, J.M., Liria, P., Olazabal, M., 2010. Social multicriteria evaluation as a decision support tool for integrated coastal zone management. Ocean and Coastal Management 53 (7), 385-403.

Gowdy, J., Erickson, J.D., 2005. The approach of ecological economics. Cambridge Journal of Economics 29, 207-222.

Herath, G., 2004. Incorporating community objectives in improved wetland management: the use of the analytic hierarchy process. Journal of Environmental Management 70 (3), 263-273.

Himes, A.H., 2007. Performance indicator importance in MPA management using a multi-criteria approach. Coastal Management 35 (5), 601-18.

Ho, W., 2008. Integrated analytic hierarchy process and its applications - a literature review. European Journal of Operational Research 186 (1), 211-228.

Innes, J.P., Pascoe, S., 2010. A multi-criteria assessment of fishing gear impacts in demersal fisheries. 
Journal of Environmental Management 91 (4), 932-939.

Ishizaka, A., Labib, A., 2011. Review of the main developments in the analytic hierarchy process. Expert Systems with Applications 38 (11), 14336-14345.

James, R.F., Blamey, R.K., 2005. Deliberation and economic valuation, national park management. In: Getzner, M., Spash, C., Stagl, S. (Eds.), Alternatives for Environmental Valuation. Routledge, USA and Canada.

Laurans, Y., Rankovic, A., Mermet, L., Billé, R., Pirard, R., 2013. Actual use of ecosystem services valuation for decision-making: questioning a literature blindspot. Journal of Environmental Management 119, 208-219.

Linkov, I., Satterstrom, F.K., Kiker, G., Batchelor, C., Bridges, T., Ferguson, E., 2006. From comparative risk assessment to multi-criteria decision analysis and adaptive management: Recent developments and applications. Environment International 32 (8), 1072-1093.

Le Gallic, B., Mardle, S., Boncoeur, J., 2005. Les objectifs d'une politique publique vus par les acteurs : une analyse multicritères de la politique commune de la pêche. Economie publique 16 (1), 127-153.

Mardle, S., Pascoe, S., Herrero, I., 2004. Management objective importance in fisheries: an evaluation using the analytic hierarchy process (AHP). Environmental Management 33 (1), 1-11.

Martinez-Alier, J., Munda, G., O`Neill, J., 1998. Weak comparability of values as a foundation for ecological economics. Ecological Economics 26 (3), 277-286.

Martín-López, B., Gómez-Baggethun, E., García-Llorente, M.., Montes, C., 2014. Trade-offs across value-domains in ecosystem services assessment. Ecological Indicators 37, 220-228.

Munda, G. 2007. Social Multi-Criteria Evaluation for a Sustainable Economy. Springer, Berlin.

Nielsen, J.R., Mathiesen, C., 2006. Stakeholder preferences for Danish fisheries management of sand eel and Norway pout. Fisheries Research 77 (1), 92-101.

O‘Neill, J., Holland, A., Light, A., 2008. Environmental Values. In: Routledge Introductions to Environment Series. Routledge Taylor and Francis Group, USA and Canada.

Pascoe, S., Proctor, W., Wilcox, C., Innes, J., Rochester, W., Dowling, N., 2009a. Stakeholder objective preferences in Australian Commonwealth managed fisheries. Marine Policy 33 (5), 750 758. 
Pascoe, S., Bustamante, R., Wilcox, C., Gibbs, M., 2009b. Spatial fisheries management: a framework for multi-objective qualitative assessment. Ocean and Coastal Management 52 (2), 130-8.

Prato, T., Herath, G., 2012. Multiple-criteria decision analysis for integrated catchment management. Ecological Economics 63 (2-3), 627-632.

Qureshi, M.E., Harrison, S.R., 2003. Application of the Analytic Hierarchy Process to Riparian Revegetation Policy Options. Small-scale Forest Economics, Management and Policy 2 (3), 441458.

Reed, M.S., 2008. Stakeholder Participation for Environmental Management: A Literature Review. Biological Conservation 141 (10), 2417- 31.

Rogers, A.A., 2013. Public and Expert Preference Divergence: Evidence from a Choice Experiment of Marine Reserves in Australia Land Economics 89 (2), 346-370.

Rogers, A.A., Kragt, M.E., Gibson, F.L., Burton, M.P., Petersen, E.H., Pannell, D.J., 2013. Nonmarket valuation: usage and impacts in environmental policy and management in Australia. Australian Journal of Agricultural and Resource Economics 59 (1), 1-15.

Saaty, T.L., 1977. A scaling method for priorities in hierarchical structures. Journal of Mathematical Psychology 15 (3), 234-281.

Saaty, T.L., 1994. Highlights and critical points in the theory and application of the Analytic Hierarchy Process. European Journal of Operational Research 74 (3), 426-447.

Saaty, T.L., Vargas, L.G., 2001. Models, Methods, Concepts and Applications of the Analytic Hierarchy Process. Kluwer, USA.

Salazar-Ordonez, M., Rodriiguez-Entrena, M., Sayadi, S., 2013. Agricultural Sustainability from a Societal View: An Analysis of Southern Spanish Citizens. Journal of Agricultural and Environmental Ethics 26 (2), 473-490.

Sipahi, Q., Timor, M., 2010. The analytic hierarchy process and analytic network process: an overview of applications. Management Decision 48 (5), 775-808.

Soma, K., 2003. How to involve stakeholders in fisheries management-a country case study in Trinidad and Tobago. Marine Policy 27 (1), 47-58.

Spash, C., Carter, C., 2001. Environmental valuation in Europe: findings from the concerted action. Environ. Valuation Europe. Policy Research Brief 11. 
Spash, C.L., 2008. Deliberative monetary valuation and the evidence for a new value theory. Land Economics 84, 469-488.

Tian, W., Bai, J., Sun, H., Zhao, Y., 2013. Application of the analytic hierarchy process to a sustainability assessment of coastal beach exploitation: A case study of the wind power projects on the coastal beaches of Yancheng, China. Journal of Environmental Management 115, 251-256.

Tsai M-C., Su, C-H., 2005. Political risk assessment of five East Asian ports: the viewpoints of global carriers. Marine Policy 29 (4), 291-298.

Vaidya, O.S., Kumar, S., 2006. Analytic hierarchy process: An overview of applications. European Journal of Operational Research 169 (1), 1-29.

Vatn, A., 2005. Rationality, institutions and environmental policy. Ecological Economics 55 (2), 203217.

Vatn, A., 2009. An institutional analysis of methods for environmental appraisal. Ecological Economics 68 (8-9), 2207-2215.

Wattage, P., Mardle, S., 2005. Stakeholder preferences towards conservation versus development for a wetland in Sri Lanka, Journal of Environmental Management 77 (2), 122-132.

Whitmarsh, D., Wattage, P., 2006. Public Attitudes Towards the Environmental Impact of Salmon Aquaculture in Scotland European Environment. European Environment 16 (2), 108-121.

Zoppi, C., 2012. A multicriteria-contingent valuation analysis concerning a coastal area of Sardinia, Italy. Land Use Policy 24 (2), 322-337. 